\title{
Impact of HEXACO Personality Factors on Consumer Video Game Engagement: A Study on eSports
}

\author{
Amir Z. Abbasi ${ }^{1 *}$, Saima Nisar ${ }^{2}$, Umair Rehman ${ }^{3}$ and Ding H. Ting ${ }^{4}$ \\ ' Faculty of Management Sciences, Shaheed Zulfiqar Ali Bhutto Institute of Science and Technology, Karachi, Pakistan, \\ ${ }^{2}$ Department of Business Management, Karakoram International University, Gilgit, Pakistan, ${ }^{3}$ User Experience Design \\ Department, Wilfrid Laurier University, Brantford, ON, Canada, ${ }^{4}$ Department of Management and Humanities, University \\ of Technology Petronas, Teronoh, Malaysia
}

OPEN ACCESS

Edited by: Bruce Ferwerda,

Jönköping University, Sweden

Reviewed by:

Naser Aghababaei,

SAMT, Iran

Petar Čolović

University of Novi Sad, Serbia

*Correspondence:

Amir Z. Abbas

aamir.zaib.abbasi@gmail.com

Specialty section:

This article was submitted to

Human-Media Interaction,

a section of the journal

Frontiers in Psychology

Received: 21 February 2020

Accepted: 02 July 2020

Published: 05 August 2020

Citation:

Abbasi AZ, Nisar S, Rehman U

and Ting $D H$ (2020) Impact

of HEXACO Personality Factors on Consumer Video Game Engagement:

A Study on eSports.

Front. Psychol. 11:1831.

doi: 10.3389/fpsyg.2020.01831
This article aims to uncover novel insights into personality factors and consumer video game engagement modeling. This research empirically validates the role of specific HEXACO personality factors that foster consumer engagement (CE) in electronic sports (eSports) users. Using a survey-based approach, we incorporated the HEXACO 60 items and consumer video game engagement scales for data collection. Data were collected from eSports users, with 250 valid responses. WarpPLS 6.0 was used for partial least squares-structural equation modeling analyses comprising measurement and structural model assessment. The results showed that the reflective measurement model is reliable and sound, whereas the second-order formative measurement model also meets the criteria of indicator weights and collinearity values variance inflation factor (VIF). The results based on the structural model indicate that openness to experience, extraversion, agreeableness, and conscientiousness positively predict CE in eSports. This article is first among others that conceptualizes and validates the HEXACO personality traits as a reflective formative model using the hierarchical component model approach. The research model carries the explanatory capacity for CE in eSports concerning personality dimensions as indicated by the HEXACO model. It highlights the potential benefits of such research especially to marketers who could potentially employ personality modeling to develop tailored strategies to increase CE in video games.

Keywords: consumer engagement, eSports, personality factors, HEXACO 60 items, PLS-SEM approach

\section{INTRODUCTION}

\section{Background}

Electronic sports (eSports) has become an emergent form of entertainment, with more than 380 million global viewers. Global consumer spending on video games is rapidly growing: from a total of $\$ 137.9 \mathrm{~B}$ in 2018 to a forecasted value of $\$ 180.1 \mathrm{~B}$ by 2021 (Pannekeet, 2018). Within gaming, competitive, tournament-based, and sport-geared video games are categorized as eSports (Jenny et al., 2017); eSports can be played real time on a myriad of platforms ranging from personal computers to gaming consoles (e.g., StarCraft II, online FIFA games (Breidbach et al., 2014; Seo and Jung, 2016). Electronic sports popularity has attracted the attention of marketers and academic scholars because of its avid-fan following (Xiao, 2019). The present research takes the first few steps toward investigating personality factors that drive consumer engagement (CE) in eSport video games. 
Extensive assessment of $\mathrm{CE}$ in games requires unified and cross-disciplinary efforts toward understanding the relationship between users and analogous game play-related products/services (Fortes Tondello et al., 2018). Video games provide avenues for engagement where users can connect and collectively participate in multifaceted game play (Hollebeek et al., 2017). Collaborative information sharing resulting from player-to-player interaction is one of the reasons for CE (U1 Islam et al., 2017) alongside other factors that are potentially shaped by an individual's unique temperamental attributes (Reyes et al., 2019). Research exploring how personality factors influence $\mathrm{CE}$ can have myriad of benefits especially from commercial standpoints; for instance, such research can aid business managers choose better market segmentation and targeting strategies based on personality-based attributes (U1 Islam et al., 2017).

Given the fact that personality is a significant factor in influencing human-computer interaction in games (Sulaiman et al., 2018), it makes sense to ascertain users' personality characteristic in efforts to develop tailored games that drive engagement in consumer game-related interactions. "Big Five" personality attributes have been extensively investigated in previous game-focused projects and others as well (Marbach et al., 2016; Ul Islam et al., 2017; Delhove and Greitemeyer, 2018; Reyes et al., 2019), with more recent research being conducted in online-game settings (Lachlan and Maloney, 2008; Alsawaier, 2018; Sulaiman et al., 2018; Shin, 2019).

The existing research has mostly employed the Big Five personality attributes, and very limited research exists that has investigated the impact of the HEXACO personality factors on $\mathrm{CE}$, especially in online video game settings. Consumer engagement is defined as "A psychological state that triggers due to two-way interactions between the consumer and video game product, i.e., eSports game, which generates a different level of consumer engagement states (cognitive, affective and behavioral)" (Abbasi et al., 2016, p. 249). As per the definition, consumer video game engagement is a higher-order formative construct that comprises three main dimensions (Abbasi et al., 2019b). Our research addresses this gap by specifically employing the fundamentally unique personality model - HEXACO, which comprises factors that include honesty-humility, emotionality, extraversion, agreeableness, conscientiousness, and openness to experience - to study the impact of personality traits on $\mathrm{CE}$ in eSports context. Prior studies investigating $\mathrm{CE}$ in video games have explored research topics such as video game addiction and scholastic achievements (Skoric et al., 2009); video games for rehabilitation (games to enhance physical therapy) (Lohse et al., 2013); mental health issues associated with video games such as stress, anxiety, and depression (Loton et al., 2016); gender differences in video game play (Jamak et al., 2018); playful-consumption experiences (Abbasi et al., 2019a,b); engagement in violent games and its link to aggressive behavior (Przybylski and Weinstein, 2019); and educational games in STEM subjects (Zuiker and Anderson, 2019). Recently, Reguera et al. (2020) have quantified engagement through playful environment, that is, video game playing.
So far, however, there is little debate on personality traits that have the potential to trigger $\mathrm{CE}$ in eSports environment. Hence, we cover this phenomenon in our study. This research is novel as we extend the concept of CE in eSports video games and explore the role of HEXACO personality factors in predicting CE. Besides, our study is first among others who conceptualizes and validates the HEXACO personality traits as a reflective formative model using the hierarchical component model approach.

\section{Rationale for Using the HEXACO Model}

The most commonly used personality trait models include the Big Five model and the "five-factor" model. Both these models carry the capacity to predict individual personality traits in terms of five major personality dimensions that include conscientiousness, agreeableness, extraversion, openness to experience, and neuroticism (Costa and McCrae, 1992). In 2000, Ashton et al. (2000) conducted a study to reassess the structure of the English personality lexicon; their research comprised lexical studies of the personality structure based on approximately a dozen languages. The outcome of their research resulted in a personality model that was later categorized as HEXACO model (Ashton et al., 2000; Ashton and Lee, 2007). HEXACO-PI-R considers the six main dimensions of personality comprising of honesty-humility $(\mathrm{H})$, emotionality (E), extraversion $(\mathrm{X})$, agreeableness $(\mathrm{A})$, conscientiousness $(\mathrm{C})$, and openness to experience (O) (Lee and Ashton, 2016). Recently, Abbasi et al. (2020) emphasized that HEXACO-PI-R was better at predicting the personality differences between individuals when compared against existing personality models. HEXACOPI-R model is akin to the Big Five model with regard to three dimensions: extraversion, conscientiousness, and openness to experience (Ashton and Lee, 2007). However, the HEXACOPI-R model presents an additional dimension, that is, honestyhumility, and modifies the existing factors such as agreeableness and emotionality of the Big Five model. Therefore, we believe that the HEXACO model is a better substitute for existing personality models including the Big Five and the five-factor models. The benefits of choosing HEXACO over existing models are manifold. For instance, HEXACO models are established on lexical studies of personality-descriptive words in multiple languages (Lee and Ashton, 2004; Ashton et al., 2014). Also, the HEXACO model offers a more comprehensive outlook on individual personality because it has additional factors that were not accounted for in existing personality models (Worth and Book, 2014). In light of its myriad of benefits, we employ the HEXACO personality model to examine the role of personality traits that influence consumers' engagement in eSport games.

\section{HYPOTHESIS DEVELOPMENT}

\section{Honesty-Humility}

According to Ashton and Lee (2009), honesty-humility is a unique characteristic of the HEXACO personality model. Individuals having this attribute are honest, modest, fair, and generous (Zeigler-Hill and Monica, 2015). They avoid manipulating other people for their gains. Individuals lacking this 
attribute are often classified as cruel, selfish, and manipulative (Andrus, 2018). To be more specific, honesty-humility is the propensity to be fair and authentic with others, even at the cost of personal suffering (Hilbig et al., 2013).

In the context of video games, individuals with pronounced personality characteristic would avoid engaging in video games. Previous research supports the notion that honesty-humility is not associated with gaming preferences (Zeigler-Hill and Monica, 2015). Honest and concerned individuals usually avoid playing video games in entirety (Worth and Book, 2014).

We thus hypothesize:

\section{H1: Honesty-humility has a negative association with consumer video game engagement.}

\section{Emotionality}

An emotional individual is often sensitive, touchy, restless, and fearful (Ashton et al., 2014). Emotionality also explains an individual's depressive tendencies and desires to seek emotional assistance (Andrus, 2018). Individual scoring high on emotionality scale are susceptible to anxiety and pain (McGrath et al., 2018).

Some studies indicate a positive relationship of emotionality with video game engagement (Worth and Book, 2014), however, in general, most studies indicate that emotional individuals avoid participating in online video games because such games can lead to disappointment or critical analysis from other players (Zeigler-Hill and Monica, 2015). According to ZeiglerHill and Monica (2015), emotionality factor is congruent to neuroticism explained by the Big Five personality factors and is negatively associated with the daredevil preferences that are common in online video games. Personalities with elevated levels of emotionality may be uncomfortable with sensation-seeking features of daredevil preferences. A highly emotional individual often tends to avoid engaging with online video games as it involves the risk of condemnation and disapproval from others. We thus hypothesize:

H2: Emotionality has a negative impact on consumer video game engagement.

\section{Extraversion}

An extravert is usually chatty, lively, dynamic, conversational, and enthusiastic (Topete, 2010). Extraverted individuals are more inclined to interact in online settings (Choi et al., 2015). According to Choi et al. (2015), extraverts are socially skillful, eager to uptake activities, and are driven to develop unique interpersonal social linkages. In the context of video games, researchers examined the positive relationship of extraversion with video game play. For example, a study related to personality and video game genres indicated a positive association of extraversion with role-playing games, action role-playing games, and real-time strategy games (Peever et al., 2012). Similarly, research suggests that progressively extraverted individuals seem to relish challenging situations often present in different game genres (Teng, 2008). Thus, we hypothesize:
H3: Extraversion has a positive association with consumer video game engagement.

\section{Agreeableness}

Highly agreeable individuals tend to be relatively more trustworthy, helpful, adaptable, accommodating, and forgiving (Choi et al., 2015). Agreeableness alludes to a cohort of positive emotions toward others and often associated with approachability and friendliness (Marbach et al., 2016). On the other hand, we also regarded agreeableness as the opposite of aggressiveness and anger. In game playing, aggressiveness and anger caused annoyance among players. A gamer who is quick and temperamental usually suffers from being criticizing during game play. Players understand that it is difficult to be accepted in the eSport community if they are aggressive. Rather than having an intolerable personality and being outcast, players have chosen to be more helpful to achieve a certain goal together. The feeling of being outcast in the eSport community or in a particular group will cause a feeling of nonbelongingness; therefore, many players have prevented the development, action, or expression of aggressiveness. The suppression effect of aggressiveness leads to a higher utility in game playing.

Highly agreeable individuals care about the contentment of others and therefore would value their commitments on online platforms (Marbach et al., 2016). Furthermore, highly agreeable personalities are more likely to report higher levels of expertise, enjoyment, and control in video games (Johnson et al., 2012). We thus hypothesize:

H4: Agreeableness has a positive association with consumer video game engagement.

\section{Conscientiousness}

Conscientiousness is a personality factor focused on achievement, success, discipline, accountability, and cautiousness (Choi et al., 2015). Conscientiousness personalities are cautious, wellorganized, and consistent in their dealings (Topete, 2010). Such individuals perform well in professional team-based settings (Lin et al., 2001). Individuals who score high in conscientiousness tend to embrace novel experiences with vigilance (Major et al., 2006). Such individuals can competently accomplish tasks by analyzing perceived information with clarity and focus; research indicates that conscientious personalities would thrive in achievementoriented environments such as online-game settings (Teng, 2008; Topete, 2010). Therefore, we hypothesize that:

H5: Conscientiousness has a positive association with consumer video game engagement.

\section{Openness to Experience}

Individuals who are open to experience tend to be more creative, versatile, open-minded, adventurous, and in pursuit of new ideas and experiences. Such personalities actively engage in shooting games, action-oriented games, role-playing, and other similar genres (Teng, 2008; Johnson and Gardner, 2010). These personalities are receptive to different types of synthetic characters and narratives present in video games 
(Johnson et al., 2012). Furthermore, it has been established that a positive association exists between openness to experience and consumer video engagement (Johnson et al., 2012; Marbach et al., 2016; McGrath et al., 2018), thereby demonstrating that individuals with high openness tend to be more receptive of video games and in general more active in video game play. Thus, we hypothesize that:

H6: Openness to experience has a positive association with consumer video game engagement.

Based on the six hypotheses above, Figure 1 portrays the relationships under study.

\section{MATERIALS AND METHODS}

\section{A Cross-Sectional Study}

A cross-sectional survey design was implemented that allowed us to gather responses instantaneously, thereby expediting the process of data collection (Mills and Gay, 2019). Another advantage of this survey approach was that it provided us with information regarding the overall behavior of our participant population.

\section{Participants}

This study involved teenagers aged between 14 and 19 years. Initially, data were gathered from different gaming zones in Rawalpindi and Islamabad. Furthermore, the study also collected data from teen students because this population has the highest tendency to actively engage in digital game-playing behavior (Adachi and Willoughby, 2016). Once we had a list of gaming zones located in both cities such as Rawalpindi and Islamabad, we then applied the randomizer tool to randomly select twenty gaming zones for data collection. Visiting each gaming zone, we first inquired whether eSports games such as CS Go, Call of Duty, PUBG, and so on, are being played. If the answer is yes, then we formally took the permission from the owner of a gaming zone and sought the consent from all eSports users (who were available at times of our visits), as well to formally start the data collection procedure. A questionnaire survey was administered to gather data from eSports users. To determine the required number of participants, we performed the power analysis using the $\mathrm{G}^{*}$ Power 3.1.9.2 (Faul et al., 2007). During the analysis, we gave the following input parameters; test family - F-tests; statistical test linear multiple regression: fixed model; $R^{2}$ deviation from zero, type of power analysis - a priori: compute required sample size given $\alpha=0.05$, power $=0.95$, and effect size $=0.15$; and number of predictors $=6$. Based on the input parameters, the recommended samples size was 146 [minimum required sample to perform partial least squares-structural equation modeling (PLS-SEM) analyses] with actual power $=0.950$.

\section{Measures and Procedure for Data Collection}

The questionnaire designed for this study has three major parts. The first part of the instrument is related to the demographics of respondents. It provides us with general information such as age, gender, qualification, frequency of video game play, average hours of play, genres of games played, commonly used platforms for game playing, and location where games are most frequently played.

The second part of the instrument is related to HEXACO personality factors adopted from the 60-item English version of the HEXACO-PI-R (Lee and Ashton, 2004, 2016). This part examines the six personality factors of our participant population, including honesty-humility, emotionality, openness to experience, agreeableness, extraversion, and conscientiousness.

The final part of the instrument is related to consumer video game engagement. Responses were collected regarding cognitive, affective, and behavioral engagement of the players with online video games. The scale was adapted from the previous literature, which has been formerly applied to assess consumer video game engagement (Abbasi et al., 2019a). We adapted this scale because it covers more aspects including cognitive, affective, and behavioral factors comparing the existing scales such as game engagement scale (Brockmyer et al., 2009), user engagement scale (Wiebe et al., 2014), and revised game engagement model (Procci et al., 2018). Besides, the dimensions of consumer video game engagement have achieved sufficient reliabilities and other validity tests (Abbasi et al., 2016, 2017, 2019a).

The main variables consist of the higher-order formative constructs from the HEXACO personality model (included the six personality factors). The individual personality factors were derived from associated aspects of participants' personality. For instance, honesty-humility involves modesty, greed avoidance, sincerity, and fairness. Emotionality was captured from fearfulness, anxiety, dependence, and sentimentality. Extraversion was extrapolated from social self-esteem, social confidence, sociability, and liveliness. Agreeableness was deduced from factors such as forgiveness, gentleness, flexibility, and patience. Conscientiousness was determined from aspects such as organization, diligence, perfectionism, and prudence. The final HEXACO personality factor called openness to experience was reasoned from aesthetic appreciation, inquisitiveness, creativity, and unconventionality (Ashton and Lee, 2009).

Similarly, consumer video game engagement stemmed from a mix of cognitive, behavioral, and emotional aspects of an individual's personality. All these three states of engagement were further elaborated: cognitive aspects were further extended into conscious attention and absorption; emotional or affective aspects were garnered from factors such as dedication and enthusiasm; and finally, behavioral engagement was surmised from factors such as social connection and interaction.

All the items in the questionnaire related to the main constructs were assessed on the Likert scales ranging from 1 to 5 (strongly disagree, disagree, neutral, agree, strongly agree).

To test the reliability of the questionnaire, a pilot study was conducted to evaluate the feasibility of the key steps, as well as to check for clarity of questions, grammatical mistakes, the feasibility of sampling technique, determining appropriate sample sizes, and reckoning overall feasibility of scale (Van Teijlingen et al., 2001). To test the reliability, we 


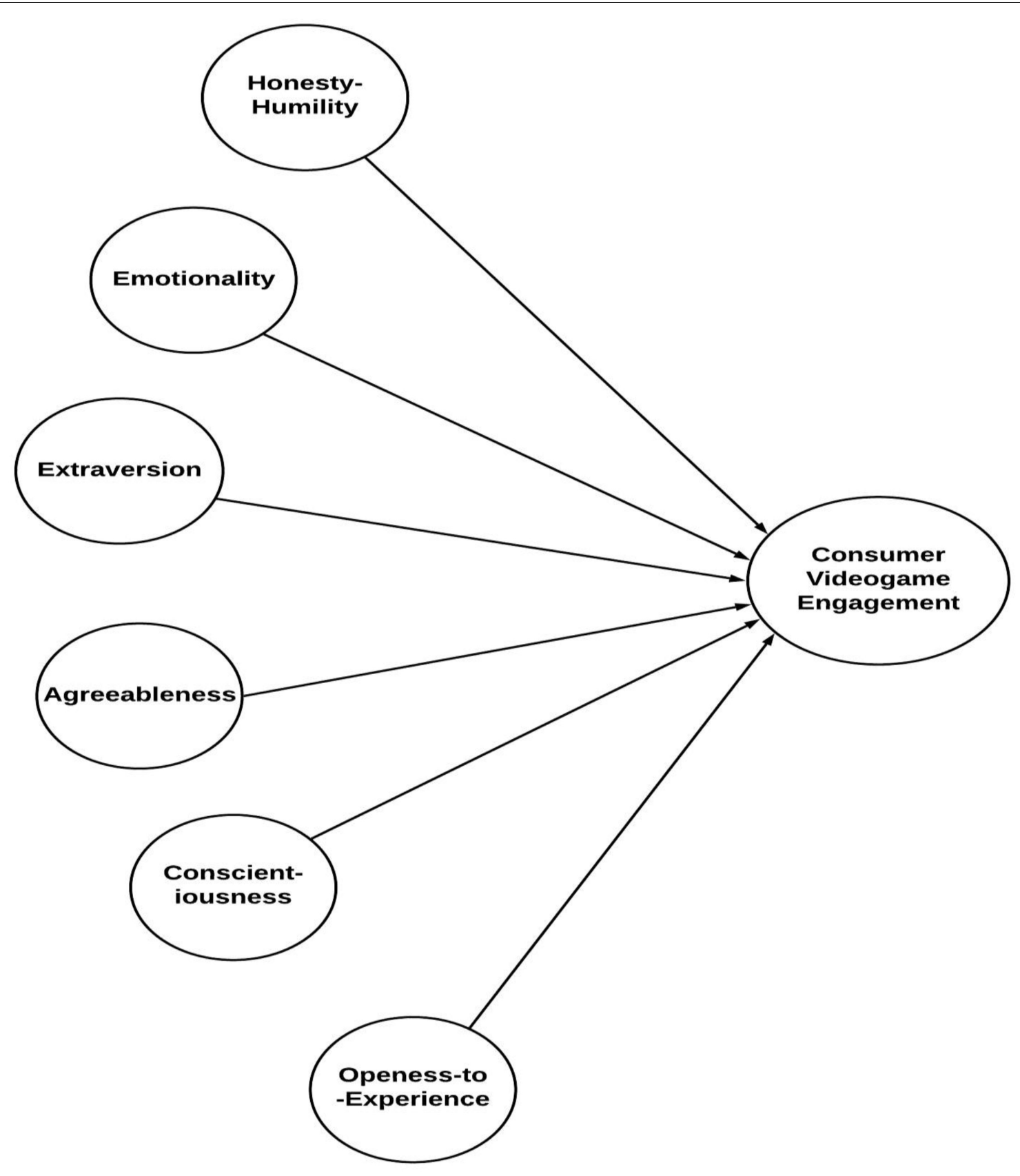

FIGURE 1 | Theoretical framework.

distributed 30 questionnaires to different respondents during the preliminary study.

Upon getting the response from the pilot study, we did some revisions, to ensure the correctness of the questionnaires as well as to ensure that a proper sampling protocol can be achieved. We then distributed 350 questionnaires, and 280 responses were collected. Once the data were collected, missing values and incomplete responses were identified and deleted using casewise deletion (Hair et al., 2016). As a result, 250 valid cases were left for further analysis, which also meets the minimum requirement for PLS-SEM analysis. See Table 1 for respondents' profile.

\section{Data Analytical Approach}

Partial least squares-structural equation modeling is a complete multivariate statistical investigation tool that was employed in this study to verify the study model (Hair et al., 2011). We applied the PLS-SEM approach because it can accommodate the testing of complex modeling (Hair et al., 2016, Hair et al., 2017). In addition, our study model comprised the 
TABLE 1 | Shows the demographic profile of the respondents.

\begin{tabular}{|c|c|}
\hline \multicolumn{2}{|l|}{ Demographic analysis } \\
\hline Respondents profile & Percentage \% \\
\hline \multicolumn{2}{|l|}{ Age } \\
\hline $14-15$ & 9.6 \\
\hline $15-16$ & 8.4 \\
\hline $17-18$ & 30.8 \\
\hline 19 & 51.2 \\
\hline \multicolumn{2}{|l|}{ Gender } \\
\hline Male & 78.8 \\
\hline Female & 21.2 \\
\hline \multicolumn{2}{|l|}{ Qualification } \\
\hline SSC & 11.2 \\
\hline Diploma/Intermediate & 34 \\
\hline Fresh Undergraduate & 28 \\
\hline Undergraduate & 26.8 \\
\hline \multicolumn{2}{|l|}{ Frequency of game playing } \\
\hline Everyday & 46 \\
\hline Once a week & 18.4 \\
\hline A few times a week & 35.6 \\
\hline \multicolumn{2}{|c|}{ Average hours of a game played } \\
\hline $1-4 \mathrm{~h}$ & 85.6 \\
\hline Above 4-8 h & 13.6 \\
\hline Above 8-12 h & .8 \\
\hline \multicolumn{2}{|c|}{ Most common games played } \\
\hline PUBG & 58 \\
\hline Counter-Strike & 93.6 \\
\hline League of Legends & 86 \\
\hline Call of duty & 84.4 \\
\hline Others & 74.4 \\
\hline \multicolumn{2}{|c|}{ The most common platform used } \\
\hline Personal computer & 58 \\
\hline Dedicated gaming console & 20.8 \\
\hline Smartphone & 80.8 \\
\hline Wireless devices & 97.2 \\
\hline Other & 2.8 \\
\hline \multicolumn{2}{|l|}{ Location of game playing } \\
\hline Home & 76.4 \\
\hline Friend's place & 12.4 \\
\hline Cyber café & 8.8 \\
\hline Others & 13.6 \\
\hline
\end{tabular}

higher-order constructs such as personality traits and consumer video game engagement. Because of the complex nature of higher-order constructs (our study involved the reflective and formative measurement models), we believe that the PLS-SEM technique can be employed for the data analyses. Moreover, our study is exploratory and based on theory development. Several studies have acknowledged that PLS-SEM is considered appropriate for exploratory studies and complex modeling involving reflective and formative constructs (Hair et al., 2017; Sarstedt et al., 2019) and theory development (Kline, 2015; Sarstedt et al., 2017). To examine the PLS-SEM analysis, our study is using the WarpPLS version 6.0, developed by Kock (2012).

\section{FINDINGS}

The present study followed a two-step process that is based on the measurement and structural model. First, the researcher assessed the measurement model for authenticating reliability and validity of the variables, and second, the structural model was appraised to explain the associations between the main variables.

\section{Step 1: Measurement Model Assessment}

The theoretical model (Figure 1) shows the two main higher model constructs that are HEXACO personality factors and the consumer video game engagement. Figure 1 further elaborates the model into the first-order, second-order, and third-order/higher-order constructs. All the personality factors are second-order formative constructs; these are derived from the first-order reflective constructs; for example, the model illustrates that honesty-humility (second-order formative construct) is derived from fairness, greed avoidance, modesty, and sincerity (these are first-order reflective constructs). Personality characteristics are further derived from other attributes, which are stated in Figure $\mathbf{2}$ and categorized as firstorder reflective or facet-level constructs for this study (Ashton et al., 2014). As explained in Figure 2, consumer video game engagement is a third-order formative construct. It is split into three main second-order formative constructs that include cognitive engagement, affective engagement, and behavioral engagement. These factors are elaborated further by firstorder reflective constructs; for example, cognitive engagement is measured through conscious attention and absorption (Abbasi et al., 2017, see Figure 2).

To evaluate the reliability and validity of the model, the study first analyzes all the first-, second-, and third-order constructs in the stated order, respectively.

\section{Assessment of First-Order Reflective Constructs}

To assess the reliability and validity of first-order reflective constructs, the study checked three criteria such as internal consistency using Cronbach $\alpha$ and composite reliability ( $>0.70$ ), outer loadings (should be $\geq 0.40$ ), convergent validity (AVE > 0.50), and discriminant validity (Sarstedt et al., 2014). The results on reflective constructs indicate that all constructs have achieved the threshold values as suggested (see Table 2).

Table 3 shows the discriminant validity for the reflective constructs. All the diagonal values reported in the table represent the square root of the AVE of each construct. To reach discriminant validity (Fornell and Larcker, 1981), this value should be greater than its parallel correlation coefficients. In the table, all the diagonal values are greater than the off-diagonal values. Thus, discriminant validity is not an issue in this study (see Table 3).

\section{Assessment of Second-Order Formative Constructs}

To assess second-order formative constructs, a two-stage method was adopted (Becker et al., 2012). To find the validity of the second-order formative construct, variance inflation factor (VIF) of all the items must be assessed, and the value should be less than five as recommended by Hair et al. (2011) or 3.3 as recommended 


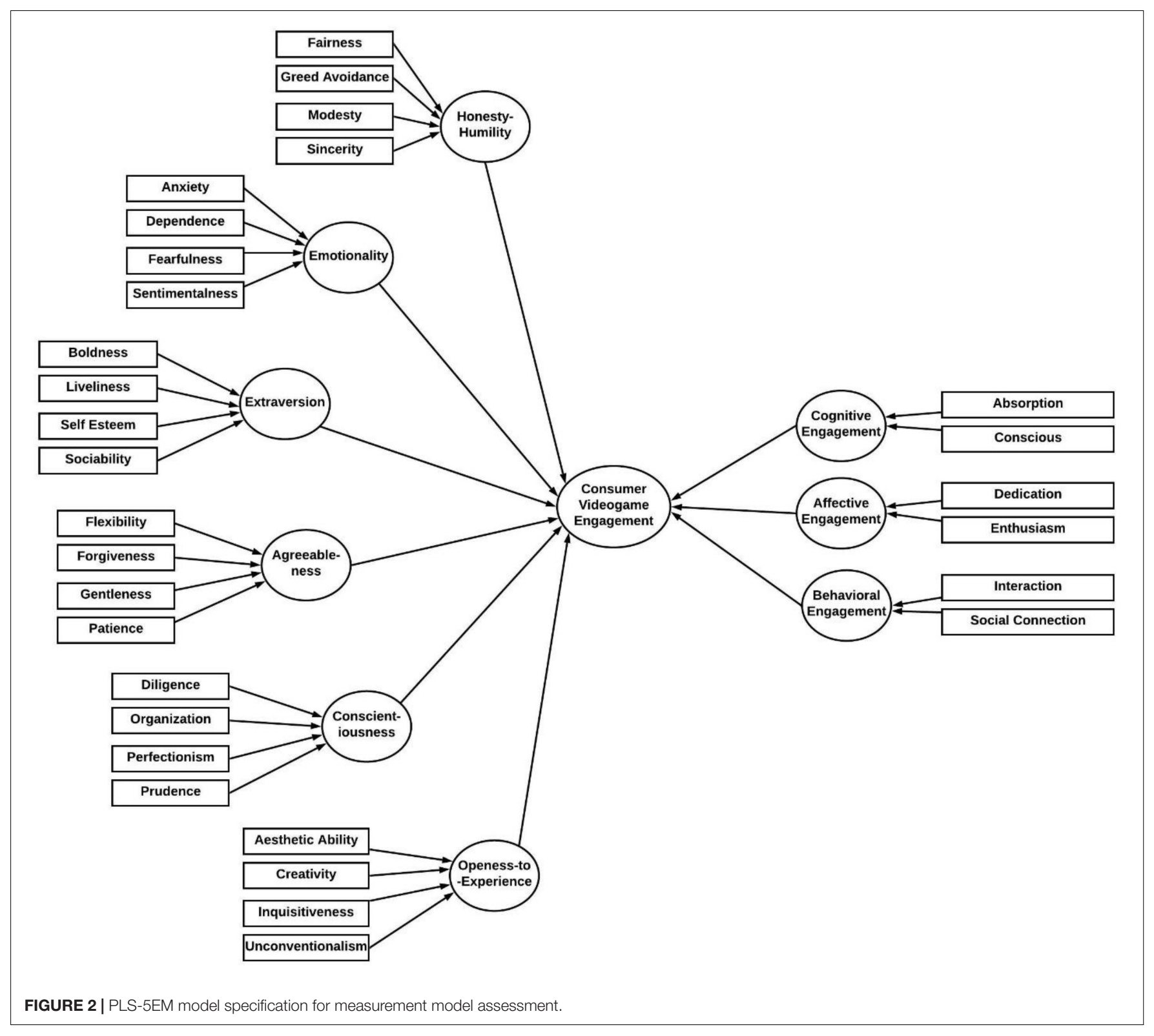

by Kock (2017). Hair et al. (2011) also emphasized that the construct's weight and significance level must be assessed. The value of the significance level must be less than 0.05 . Table 4 reveals the significance or $P$-value of indicator weights associated with second-order formative constructs and VIF of the variables; these values in Table 4 match the discussed threshold criteria. Hence, our second-order formative constructs are valid and reliable for further analysis (see Table 4).

\section{Assessment of Third-Order/Higher-Order Formative Construct}

Again, to assess the validity of the third-order construct, that is consumer video game engagement, the study used WarpPLS version 6.0. Initially, the value of VIF was assessed, and then the significance level of the indicator's weight was checked. Table 5 shows the values of VIF, indicator weights, and their significance level. All the values of each construct have VIF below five, and associated indicator weights meet the significance level except the affective engagement. Under such situation, Hair et al. (2016) recommended to assess the outer loading of the item, and if the outer loadings exceed the value of 0.40 , then we can keep an item. Following the guideline, we examined the outer loading for affective engagement and found that it exceeded the critical value of 0.40 . Therefore, these values confirm the validity of the third-order formative construct also (see Table 5).

\section{Step 2: Structural Model Assessment}

The study used WarpPLS version 6.0 to check the framework model and hypotheses. For this, we assessed the value of path coefficient with effect size and $T$-value and the significance of the $R^{2}$ coefficient. Effect size measures the impact of the independent 
TABLE 2 | Assessment of measurement model.

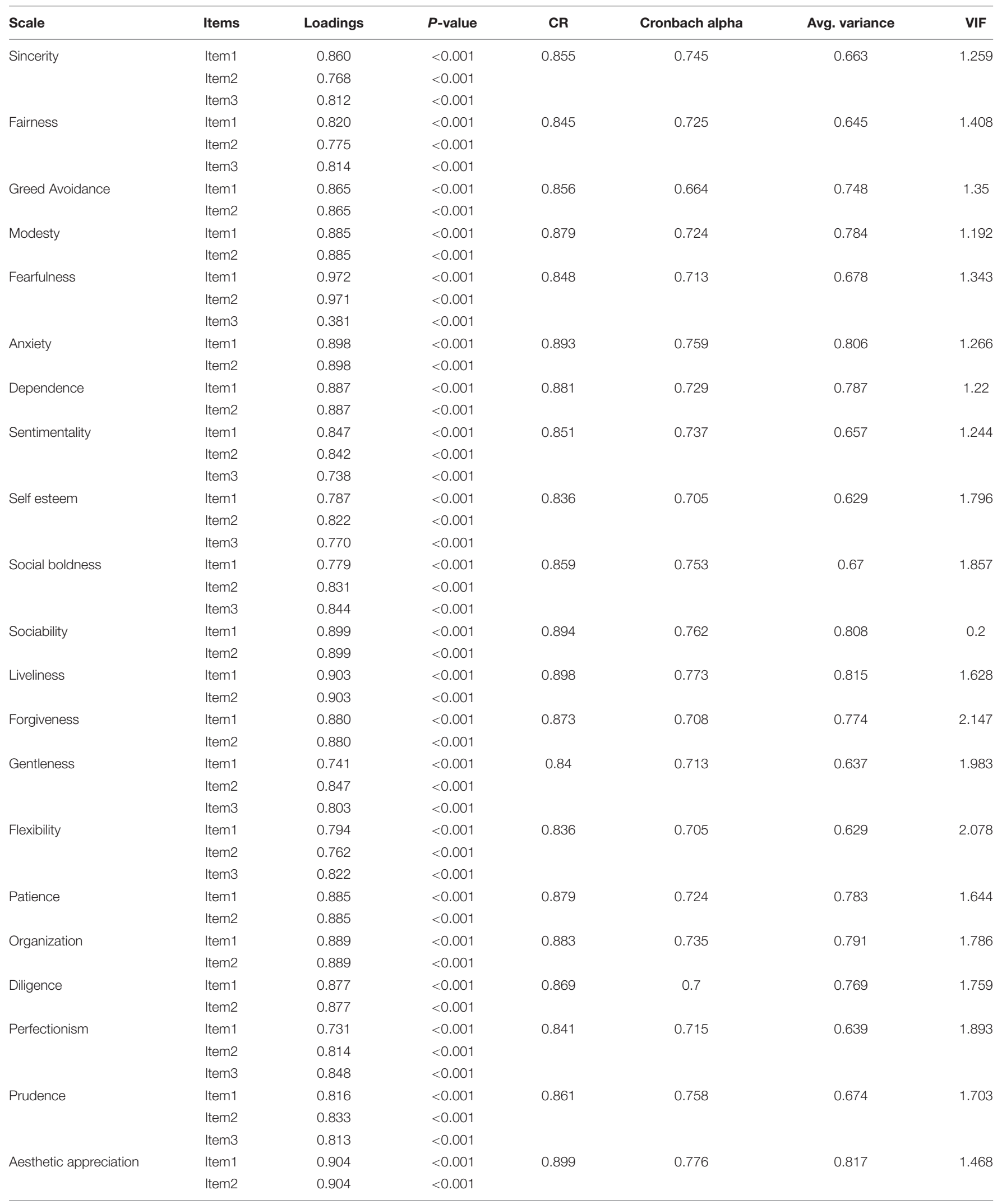


TABLE 2 | Continued

\begin{tabular}{|c|c|c|c|c|c|c|c|}
\hline Scale & Items & Loadings & $P$-value & CR & Cronbach alpha & Avg. variance & VIF \\
\hline \multirow[t]{2}{*}{ Inquisitiveness } & Item1 & 0.894 & $<0.001$ & 0.888 & 0.748 & 0.799 & 1.956 \\
\hline & Item2 & 0.894 & $<0.001$ & & & & \\
\hline \multirow[t]{3}{*}{ Creativity } & Item1 & 0.810 & $<0.001$ & 0.836 & 0.704 & 0.63 & 1.714 \\
\hline & Item2 & 0.850 & $<0.001$ & & & & \\
\hline & Item3 & 0.715 & $<0.001$ & & & & \\
\hline \multirow[t]{3}{*}{ Unconventionality } & Item1 & 0.853 & $<0.001$ & 0.846 & 0.727 & 0.648 & 1.446 \\
\hline & Item2 & 0.792 & $<0.001$ & & & & \\
\hline & Item3 & 0.767 & $<0.001$ & & & & \\
\hline \multirow[t]{6}{*}{ Conscious attention } & Item1 & 0.713 & $<0.001$ & 0.883 & 0.841 & 0.558 & 3.052 \\
\hline & Item2 & 0.774 & $<0.001$ & & & & \\
\hline & Item3 & 0.763 & $<0.001$ & & & & \\
\hline & Item4 & 0.764 & $<0.001$ & & & & \\
\hline & Item5 & 0.756 & $<0.001$ & & & & \\
\hline & Item6 & 0.711 & $<0.001$ & & & & \\
\hline \multirow[t]{5}{*}{ Absorption } & Item1 & 0.737 & $<0.001$ & 0.874 & 0.819 & 0.581 & 3.084 \\
\hline & Item2 & 0.774 & $<0.001$ & & & & \\
\hline & Item3 & 0.766 & $<0.001$ & & & & \\
\hline & Item4 & 0.751 & $<0.001$ & & & & \\
\hline & Item5 & 0.781 & $<0.001$ & & & & \\
\hline \multirow[t]{5}{*}{ Dedication } & Item1 & 0.873 & $<0.001$ & 0.895 & 0.846 & 0.641 & 2.188 \\
\hline & Item2 & 0.885 & $<0.001$ & & & & \\
\hline & Item3 & 0.874 & $<0.001$ & & & & \\
\hline & Item4 & 0.435 & $<0.001$ & & & & \\
\hline & Item5 & 0.841 & $<0.001$ & & & & \\
\hline \multirow[t]{3}{*}{ Enthusiasm } & Item1 & 0.877 & $<0.001$ & 0.901 & 0.834 & 0.752 & 2.321 \\
\hline & Item2 & 0.906 & $<0.001$ & & & & \\
\hline & Item3 & 0.815 & $<0.001$ & & & & \\
\hline \multirow[t]{3}{*}{ Social connection } & Item1 & 0.816 & $<0.001$ & 0.863 & 0.762 & 0.677 & 2.424 \\
\hline & Item2 & 0.815 & $<0.001$ & & & & \\
\hline & Item3 & 0.837 & $<0.001$ & & & & \\
\hline \multirow[t]{5}{*}{ Interaction } & Item1 & 0.731 & $<0.001$ & 0.884 & 0.836 & 0.604 & 3.313 \\
\hline & Item2 & 0.776 & $<0.001$ & & & & \\
\hline & Item3 & 0.801 & $<0.001$ & & & & \\
\hline & Item4 & 0.831 & $<0.001$ & & & & \\
\hline & Item5 & 0.743 & $<0.001$ & & & & \\
\hline
\end{tabular}

variable on the dependent variable. According to the values of the effect size given in Table 6, we conclude the following:

- Players' honesty-humility and emotionality factors have no effect on predicting consumer video game engagement.

- In contrast, players' conscientiousness, openness to experience, agreeableness, and extraversion factors have more than a small effect on developing consumer video game engagement. Hence, our proposed hypotheses are accepted.

In addition to the effect size, we also calculated the $P$-value, $T$-value, and path coefficient for our study hypotheses. The results shown in Table 6 illustrated that honesty-humility has an insignificant relationship with consumer video game engagement (path $=0.065 ; T=1.03 ; P=0.15)-\mathrm{H} 1$ is not accepted. Furthermore, the path coefficient, $T$-value, and $P$-value for depicting the relationship between emotionality and consumer video game engagement are 0.07, 1.12, and 0.132, respectively. Because this does not meet the set criteria, our second hypothesis is also rejected. This means that there is no significant relationship between emotionality and consumer video game engagement - hence, $\mathrm{H} 2$ is not supported. Extraversion has a significant relationship with consumer video game engagement with a path coefficient of $0.145, T$-value of 2.33 , and $P$-value of $0.01-$ and as a result, H3 is accepted. Similarly, agreeableness, conscientiousness, and openness to experience have path coefficient values of $0.232,0.184$, and 0.177 and $T$-values of $3.8,2.87$, and 2.9 , respectively. Also, the $P$-values shown in the table are $<0.001,0.002$, and 0.002 accordingly - therefore, H4, H5, and H6 are accepted. See Table 6 and Figure 3 for more details.

In addition, we examined the correlations between the personality traits, and the results showed that there is no high correlation issue. See Table 7 for more details. 
TABLE 3 | Discriminant validity.

\begin{tabular}{|c|c|c|c|c|c|c|c|c|c|c|c|}
\hline & HSin & Hfair & Hgred & Efear & \multicolumn{2}{|c|}{ Eanxity } & Edep & Esenti & Eslfest & Ebold & Esoc \\
\hline Hfair & 0.201 & 0.8 & & & & & & & & & \\
\hline Efearfu & 0.173 & 0.21 & 0.229 & 0.823 & & & & & & & \\
\hline Enxity & 0.129 & 0 & 0.201 & 0.187 & \multicolumn{2}{|c|}{0.898} & & & & & \\
\hline Edep & 0.162 & 0.16 & 0.186 & 0.152 & \multicolumn{2}{|c|}{0.237} & 0.887 & & & & \\
\hline Eslfest & -0.03 & 0.09 & -0.01 & 0.066 & \multicolumn{2}{|c|}{-0.053} & 0.062 & 0.077 & 0.793 & & \\
\hline Ebold & 0.065 & 0.16 & 0.074 & 0.155 & \multicolumn{2}{|c|}{0.091} & 0.141 & 0.143 & 0.471 & 0.818 & \\
\hline \multirow[t]{2}{*}{ Esoc } & 0.09 & 0.1 & 0.099 & 0.196 & \multicolumn{2}{|c|}{0.114} & 0.011 & 0.134 & 0.428 & 0.45 & 0.899 \\
\hline & ELivli & Aforg & Agent & Aflex & Apat & Corg & Cdelg & Cperf & Cprud & Oaest & Oinqu \\
\hline ELivli & 0.903 & & & & & & & & & & \\
\hline Apatnc & 0.202 & 0.425 & 0.36 & 0.455 & 0.885 & & & & & & \\
\hline Corg & 0.269 & 0.259 & 0.264 & 0.209 & 0.275 & 0.889 & & & & & \\
\hline Cdelig & 0.206 & 0.263 & 0.123 & 0.19 & 0.333 & 0.456 & 0.877 & & & & \\
\hline Cperf & 0.217 & 0.261 & 0.226 & 0.316 & 0.338 & 0.469 & 0.447 & 0.799 & & & \\
\hline Cprud & 0.177 & 0.136 & 0.133 & 0.352 & 0.261 & 0.316 & 0.304 & 0.428 & 0.821 & & \\
\hline Oaesth & 0.118 & 0.191 & 0.191 & 0.329 & 0.327 & 0.216 & 0.265 & 0.274 & 0.184 & 0.904 & \\
\hline \multirow[t]{2}{*}{ Oinqu } & 0.402 & 0.419 & 0.402 & 0.377 & 0.419 & 0.292 & 0.314 & 0.397 & 0.256 & 0.392 & 0.894 \\
\hline & Creat & \multicolumn{2}{|c|}{ Unc } & ConAt & Asorp & \multicolumn{2}{|c|}{ Dedic } & \multicolumn{2}{|c|}{ Enthu } & Socon & Interc \\
\hline Creatit & 0.794 & & & & & & & & & & \\
\hline Uncon & 0.29 & \multicolumn{2}{|c|}{0.805} & & & & & & & & \\
\hline
\end{tabular}

Square roots of average variances extracted (AVES) shown on diagonal.

\section{DISCUSSION}

With the addition of different gaming platforms, eSport video game is rapidly gaining prominence in the gaming industry. This study employs the HEXACO personality model to establish a relationship between consumer personality and consumer video game engagement in the context of eSports. Quantitative methods were employed in this research, and HEXACO-PI-R 60 items were used to investigate the personalities of consumers engaged in eSports. The study empirically tested and validated the proposed model using WarpPLS version 6.0 for SEM analysis. This research presents novel insights in uncovering the specific personality factors that drive consumers' video game engagement.

According to the data analysis, honesty-humility, and emotionality factors carry an insignificant impact on consumer video game engagement, whereas extraversion, agreeableness, consciousness, and openness to experience have a significant effect on consumer video game engagement.

As mentioned earlier, our first hypothesis indicates that honesty-humility has an insignificant impact on consumer video game engagement. Previously, Worth and Book (2014) also empirically tested this premise; they demonstrated that personalities covering the characteristic are less inclined to engage in player-versus-player-style games. Furthermore, games that involve profit manipulation, rule breaking, and material gain are also correlated with a low characteristic of honesty-humility (Andrus, 2018). Insignificant association of this attribute with consumer video game engagement is also demonstrated by Zeigler-Hill and Monica (2015). Games involve exploitation and strategic maneuvering, which can be less appealing for individuals who score high on honesty-humility.

Our second hypothesis revealed an insignificant relationship of emotionality with consumer video game engagement. In prior studies, a negative relationship was also confirmed between 
TABLE 4 | Assessment of the measurement model on second-order formative constructs (e.g., honesty-humility, emotionality, and etc.).

\begin{tabular}{|c|c|c|c|c|c|c|}
\hline Constructs & Items & Scale type & Weights & Sig & Full collinearity & VIF \\
\hline \multirow[t]{4}{*}{ Honesty-humility } & & Formative & & & 1.153 & \\
\hline & Sincerity & & 0.452 & $<0.001$ & & 1.08 \\
\hline & Fairness & & 0.48 & $<0.001$ & & 1.136 \\
\hline & Greed avoidance & & 0.499 & $<0.001$ & & 1.134 \\
\hline \multirow[t]{5}{*}{ Emotionality } & & Formative & & & 1.166 & \\
\hline & Fearfulness & & 0.33 & $<0.001$ & & 1.05 \\
\hline & Anxiety & & 0.466 & $<0.001$ & & 1.132 \\
\hline & Dependence & & 0.42 & $<0.001$ & & 1.089 \\
\hline & Sentimentality & & 0.383 & $<0.001$ & & 1.077 \\
\hline \multirow[t]{5}{*}{ Extraversion } & & Formative & & & 1.7 & \\
\hline & Social self esteem & & 0.323 & $<0.001$ & & 1.402 \\
\hline & Social boldness & & 0.338 & $<0.001$ & & 1.473 \\
\hline & Sociability & & 0.346 & $<0.001$ & & 1.527 \\
\hline & Liveliness & & 0.317 & $<0.001$ & & 1.376 \\
\hline \multirow[t]{5}{*}{ Agreeableness } & & Formative & & & 2.007 & \\
\hline & Forgiveness & & 0.333 & $<0.001$ & & 1.545 \\
\hline & Gentleness & & 0.33 & $<0.001$ & & 1.552 \\
\hline & Flexibility & & 0.335 & $<0.001$ & & 1.557 \\
\hline & Patience & & 0.304 & $<0.001$ & & 1.372 \\
\hline \multirow[t]{5}{*}{ Conscientiousness } & & Formative & & & 1.526 & \\
\hline & Organization & & 0.343 & $<0.001$ & & 1.436 \\
\hline & Diligence & & 0.336 & $<0.001$ & & 1.398 \\
\hline & Perfectionism & & 0.361 & $<0.001$ & & 1.54 \\
\hline & Prudence & & 0.3 & $<0.001$ & & 1.263 \\
\hline \multirow[t]{5}{*}{ Openness-to-experience } & & Formative & & & 1.787 & \\
\hline & Aesthetic app & & 0.347 & $<0.001$ & & 1.286 \\
\hline & Inquisitiveness & & 0.373 & $<0.001$ & & 1.396 \\
\hline & Creativity & & 0.364 & $<0.001$ & & 1.361 \\
\hline & Unconventionality & & 0.303 & $<0.001$ & & 1.172 \\
\hline \multirow[t]{3}{*}{ Cognitive engagement } & & Formative & & & 3.470 & \\
\hline & Conscious attention & & 0.551 & $<0.001$ & & 1.731 \\
\hline & Absorption & & 0.551 & $<0.001$ & & 1.731 \\
\hline \multirow[t]{3}{*}{ Affective engagement } & & Formative & & & 2.673 & \\
\hline & Dedication & & 0.566 & $<0.001$ & & 1.454 \\
\hline & Enthusiasm & & 0.566 & $<0.001$ & & 1.454 \\
\hline \multirow[t]{3}{*}{ Behavioral engagement } & & Formative & & & 3.224 & \\
\hline & Social connection & & 0.553 & $<0.001$ & & 1.682 \\
\hline & Interaction & & 0.553 & $<0.001$ & & 1.682 \\
\hline
\end{tabular}

TABLE $\mathbf{5}$ | Assessment of the measurement model of higher-order formative construct (consumer videogame engagement).

\begin{tabular}{|c|c|c|c|c|c|c|}
\hline Constructs & Items & Scale type & Weights & Sig & Full Collinearity & VIF \\
\hline \multirow[t]{4}{*}{ Consumer VGE } & & Formative & & & 1.549 & \\
\hline & Cognitive Eng & & 0.468 & $<0.001$ & & 3.360 \\
\hline & Affective Eng & & 0.072 & 0.125 & & 2.644 \\
\hline & Behavioral Eng & & 0.526 & $<0.001$ & & 3.089 \\
\hline
\end{tabular}

emotionality and daredevil preferences (Zeigler-Hill and Monica, 2015). It is important to highlight that emotional individuals prefer to avoid challenging scenarios where there is a likelihood to receive negative feedback and social disapproval. Furthermore, emotional individuals tend to demonstrate dour outlooks, which can aggravate in gaming contexts. Therefore, it is not surprising that emotionality factor does not indicate a positive association with consumer video game engagement.

Our third hypothesis of the study showed a positive relationship of extraversion with consumer video game engagement. Previous literature also confirms the presence of an insignificant relation in the context of player game preferences (Andrus, 2018), video game preferences (ZeiglerHill and Monica, 2015), and game-playing style (Bean and Groth-Marnat, 2016). Generally, personalities that are social, optimistic, and confident actively engage in video games because gaming environments appeal to their individual psychosomatic inclinations.

Our fourth hypothesis shows a positive relationship between agreeableness and consumer video game engagement. In previous 
TABLE 6 | Assessment of the structural model.

\begin{tabular}{|c|c|c|c|c|c|c|c|}
\hline Hypothesis testing & & Path coefficient & SE & F2 & $T$-value & $P$-value & Result \\
\hline H1: Honesty-humility & Con VGE & 0.065 & 0.063 & 0.012 & 1.03 & 0.15 & Not supported \\
\hline H2: Emotionality & Con VGE & 0.07 & 0.062 & 0.014 & 1.12 & 0.132 & Not supported \\
\hline H3: Extraversion & Con VGE & 0.145 & 0.062 & 0.067 & 2.33 & 0.01 & Supported \\
\hline H4: Agreeableness & Con VGE & 0.232 & 0.061 & 0.115 & 3.8 & $<0.001$ & Supported \\
\hline H5: Conscientiousness & Con VGE & 0.184 & 0.061 & 0.08 & 2.87 & 0.002 & Supported \\
\hline H6: Openness to Exp & Con VGE & 0.177 & 0.061 & 0.084 & 2.9 & 0.002 & Supported \\
\hline
\end{tabular}

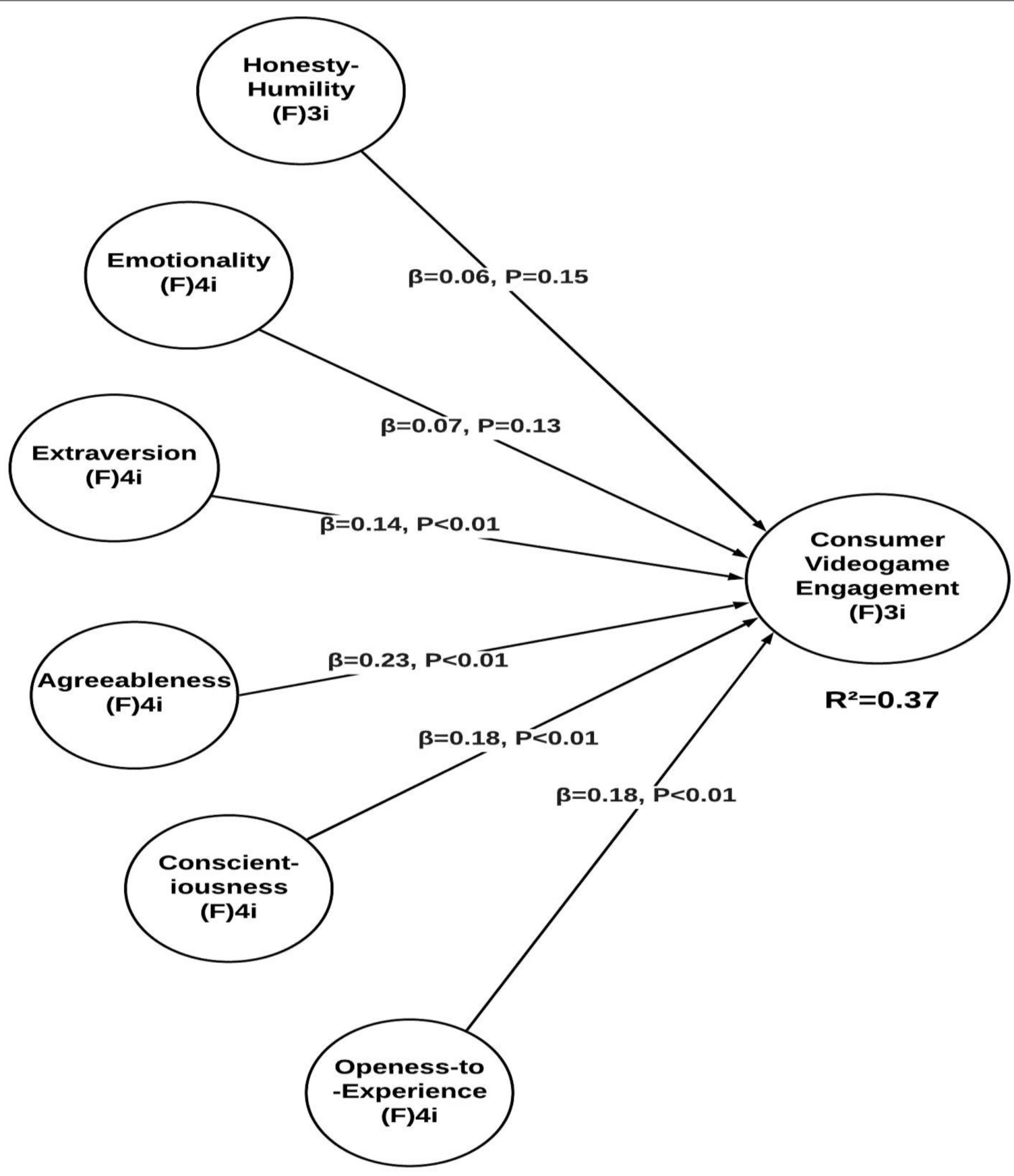


TABLE 7 | Correlations matrix using HEXACO 60-item English version.

\begin{tabular}{lrccccr}
\hline & H & E & X & A & C & O \\
\hline Honesty-humility & 1 & & & & & \\
Emotionality & 0.324 & 1 & & & & \\
Extraversion & 0.078 & 0.209 & 1 & & & \\
Agreeableness & -0.033 & 0.121 & 0.580 & 1 & & \\
Conscientiousness & 0.019 & 0.036 & 0.385 & 0.429 & 1 & \\
Openness to experience & 0.092 & 0.104 & 0.419 & 0.544 & 0.546 & 1 \\
\hline
\end{tabular}

research, agreeableness dimension carries a positive correlation in multiplayer games environment and "helping" style games (Worth and Book, 2014), as well as a positive correlation with a preference to play challenging games (Zeigler-Hill and Monica, 2015). So, individuals with this attribute are adaptable and understanding and carry the proclivity to engage in games for social rapport or entertainment purposes actively.

Our fifth hypothesis shows that consciousness has a positive association with consumer video game engagement. In previous research, conscious individuals have demonstrated achievementoriented behaviors in game-based settings (Zeigler-Hill and Monica, 2015). Zeigler-Hill and Monica (2015) have indicated that individuals with high consciousness scores prefer games that involve accomplishing arduous tasks or solving challenges rather than indulging in game play purely for leisure purposes. Therefore, from our study, we can conclude that well-organized, disciplined, and careful individuals prefer to invest time in experiencing different genres of thought-provoking games.

Our final hypothesis shows a positive relationship between openness to experience with consumer video game engagement. Literature confirms the same relationship: for instance, a study revealed that online-game players are higher in openness to experience than nonplayers (Teng, 2008). Also, openness to experience is associated with the gratification of play and shows the highest positive association for unique game behavior predilections (Bean and Groth-Marnat, 2016; Andrus, 2018). Therefore, we can say that individuals with openness to experience are eager to seek new information and are creative, imaginative, and adaptable; the presence of such psychographics results in a greater drive for engagement in video games.

\section{IMPLICATIONS AND FURTHER RESEARCH}

\section{Theoretical Implications}

This study makes several theoretical contributions. First, we present an empirical study of the HEXACO personality model and its association with consumer video game engagement in the context of eSports. Previous literature added that Big Five personality dimensions carry an impact on CE in the context of online brand communities such as social media platforms (Ul Islam et al., 2017). However, we extend the existing literature on personality traits, especially focusing on video game studies through investigating a novel model, that is, HEAXCO in the realm of consumer behavior and eSports settings. We demonstrate that certain dimensions of the HEXACO model contribute to driving $\mathrm{CE}$ in eSports. Second, this study also adds value to the current gaming research within the marketing literature. This research can aid researchers and marketers that are interested in analyzing empirical work that investigates CE with the video game industry. Third, we advance the earlier studies on personality traits through applying the hierarchical component model approach (Becker et al., 2012; Sarstedt et al., 2019) to establish and validate higher-order constructs. Fourth, we contribute to the notion of consumer video game engagement as we provide the evidence that personality traits do impact on $\mathrm{CE}$ in eSports context.

\section{Managerial Implications}

This study also makes critical managerial contributions. First, this article highlights how marketers can capitalize on consumers' personality factors by focusing their investments on specific personality attributes that are predicted to optimize video game engagement. Secondly, our model offers marketing practitioners the opportunity to develop video game strategies based on their target consumers' personality factors and their expected effect on CE, which are extremely substantial in today's era of one-to-one marketing and big data analytics. Third, video game developers can also develop specific games by capturing consumer's interest according to each personality factor; thus, ultimately, their market share and overall growth in the industry can be maximized. A clearer picture of consumers' personality characteristics may also help practitioners garner a better understanding of how to strategically build a process to engage customers in video game settings actively.

\section{Future Research}

Despite its contributions, this study is still in its exploratory stage to understand the personality factors and consumer video game engagement and therefore subjected to several limitations. The first limitation is on the assumption that gamers and eSport gamers are assumed to take on the role as what is observed. With the six attributes that we have identified, we have taken the eSport gamers and personalities on the face value. We believe that it is also important to understand what takes place throughout the development of the attitude and behavior of these gamers. This could be done by using a longitudinal study (development of behavior through a process of sampling different sample groups) or conducting an experiment on the personality traits that are captured in the HEXACO 60 items. In experimental studies, control groups should be able to mobilize to capture the effects of the personalities. Second, to validate the HEXACO 60 items, the sample size is relatively small and focused on respondents from Pakistan. For a better generalization, there should be efforts to collect more samples, not only within a country but also to simultaneously expand the data collection to different countries (to capture the differences in cultures as well). Third, our study is limited in terms of the scope of its investigation within the context of eSports, whereas this study can also be extended to other genres of video games including intellectual games or virtual reality 
games and to investigate how consumers' personality characteristics predict consumers' preferred game-product preferences. Fourthly, with the advent of eSport gaming, games are not only played by men, but also by women. We acknowledge the unbalanced gender distribution in our study. Care should be taken to include a better representation of gender distribution in future studies. The condition of nongamers versus gamers (or occasional gamers) should also be defined, to understand and capture the unprecedented conditions and personality differences.

\section{DATA AVAILABILITY STATEMENT}

The datasets generated for this study are available on request to the corresponding author.

\section{REFERENCES}

Abbasi, A. Z., Ting, D. H., and Hlavacs, H. (2016). "A revisit of the measurements on engagement in videogames: a new scale development," in International Conference on Entertainment Computing, eds G. Wallner, S. Kriglstein, H. Hlavacs, R. Malaka, A. Lugmayr, and H. S. Yang (Cham: Springer), 247-252. doi: 10.1007/978-3-319-46100-7_25

Abbasi, A. Z., Ting, D. H., and Hlavacs, H. (2017). Engagement in games: developing an instrument to measure consumer videogame engagement and its validation. Int. J. Comput. Games Technol. 2017:7363925.

Abbasi, A. Z., Ting, D. H., Hlavacs, H., Costa, L. V., and Veloso, A. I. (2019a). An empirical validation of consumer video game engagement: a playfulconsumption experience approach. Entertain. Comput. 29, 43-55. doi: 10.1016/ j.entcom.2018.12.002

Abbasi, A. Z., Ting, D. H., Hlavacs, H., Fayyaz, M. S., and Wilson, B. (2019b). "Playful-consumption experience and consumer videogame engagement in the lens of S-R model: an empirical study," in International Conference on HumanComputer Interaction, ed. X. Fang (Cham: Springer), 85-104. doi: 10.1007/9783-030-22602-2_8

Abbasi, A. Z., Ting, D. H., Hlavacs, H., Wilson, B., Rehman, U., and Arsalan, A. (2020). Personality differences between videogame vs. non-videogame consumers using the HEXACO model. Curr. Psychol. doi: 10.1007/s12144-02000793-2

Adachi, P. J., and Willoughby, T. (2016). Does playing sports video games predict increased involvement in real-life sports over several years among older adolescents and emerging adults? J. Youth Adolesc. 45, 391-401. doi: 10.1007/ s10964-015-0312-2

Alsawaier, R. S. (2018). The effect of gamification on motivation and engagement. Int. J. Inf. Learn. Technol. 35, 56-79. doi: 10.1108/ijilt-02-20170009

Andrus, K. H. K. (2018). Personality \& Game Design Preference: Towards Understanding Player Engagement and Behavior. Lund: Lund University.

Ashton, M. C., and Lee, K. (2007). Empirical, theoretical, and practical advantages of the HEXACO model of personality structure. Pers. Soc. Psychol. Rev. 11, 150-166. doi: 10.1177/1088868306294907

Ashton, M. C., and Lee, K. (2009). The HEXACO-60: a short measure of the major dimensions of personality. J. Pers. Assess. 91, 340-345. doi: 10.1080/ 00223890902935878

Ashton, M. C., Lee, K., and de Vries, R. E. (2014). The HEXACO honesty-humility, agreeableness, and emotionality factors a review of research and theory. Pers. Soc. Psychol. Rev. 18, 139-152. doi: 10.1177/1088868314523838

Ashton, M. C., Lee, K., and Son, C. (2000). Honesty as the sixth factor of personality: correlations with Machiavellianism, primary psychopathy, and social adroitness. Eur. J. Pers. 14, 359-368. doi: 10.1002/1099-0984(200007/08) 14:4<359::aid-per382>3.0.co;2-y

\section{ETHICS STATEMENT}

The studies involving human participants were reviewed and approved by the Departmental Ethical Review Committee Shaheed Zulfikar Ali Bhutto Institute of Science and Technology (Szabist). The patients/participants provided their written informed consent to participate in this study.

\section{AUTHOR CONTRIBUTIONS}

AA, SN, and UR worked on the idea development and conceptual design. SN and AA worked on the data analyses. SN, UR, AA, and DT edited the manuscript and improved the contents of the manuscript. All authors contributed to the article and approved the submitted version.

Bean, A., and Groth-Marnat, G. (2016). Video gamers and personality: a five-factor model to understand game playing style. Psychol. Pop. Media Cult. 5, 27-38. doi: $10.1037 / \mathrm{ppm} 0000025$

Becker, J.-M., Klein, K., and Wetzels, M. (2012). Hierarchical latent variable models in PLS-SEM: guidelines for using reflective-formative type models. Long Range Plann. 45, 359-394. doi: 10.1016/j.lrp.2012.10.001

Breidbach, C., Brodie, R., and Hollebeek, L. (2014). Beyond virtuality: from engagement platforms to engagement ecosystems. Manag. Serv. Qual. 24, 592-611. doi: 10.1108/msq-08-2013-0158

Brockmyer, J. H., Fox, C. M., Curtiss, K. A., McBroom, E., Burkhart, K. M., and Pidruzny, J. N. (2009). The development of the game engagement questionnaire: a measure of engagement in video game-playing. J. Exp. Soc. Psychol. 45, 624-634. doi: 10.1016/j.jesp.2009.02.016

Choi, D., Oh, I.-S., and Colbert, A. E. (2015). Understanding organizational commitment: a meta-analytic examination of the roles of the five-factor model of personality and culture. J. Appl. Psychol. 100, 1542-1567. doi: 10.1037/ apl0000014

Costa, P. T. Jr., and McCrae, R. R. (1992). Four ways five factors are basic. Pers. Individ. Dif. 13, 653-665. doi: 10.1016/0191-8869(92)90236-i

Delhove, M., and Greitemeyer, T. (2018). The relationship between video game character preferences and aggressive and pro-social personality traits. Psychol. Pop. Media 9, 96-104. doi: 10.1037/ppm0000211

Faul, F., Erdfelder, E., Lang, A.-G., and Buchner, A. (2007). G* Power 3: a flexible statistical power analysis program for the social, behavioral, and biomedical sciences. Behav. Res. Methods 39, 175-191. doi: 10.3758/bf03193146

Fornell, C., and Larcker, D. F. (1981). Evaluating structural equation models with unobservable variables and measurement error. J. Mark. Res. 18, 39-50. doi: $10.1177 / 002224378101800104$

Fortes Tondello, G., Valtchanov, D., Reetz, A., Wehbe, R. R., Orji, R., and Nacke, L. E. (2018). Towards a trait model of video game preferences. Int. J. Hum. Comput. Interact. 34, 732-748. doi: 10.1080/10447318.2018.1461765

Hair, J., Hollingsworth, C. L., Randolph, A. B., and Chong, A. Y. L. (2017). An updated and expanded assessment of PLS-SEM in information systems research. Ind. Manag. Data Syst. 117, 442-458. doi: 10.1108/imds-04-20160130

Hair, J. F. Jr., Hult, G. T. M., Ringle, C., and Sarstedt, M. (2016). A Primer on Partial Least Squares Structural Equation Modeling (PLS-SEM). London: Sage Publications.

Hair, J. F., Ringle, C. M., and Sarstedt, M. (2011). PLS-SEM: indeed a silver bullet. J. Mark. Theory Pract. 19, 139-152. doi: 10.2753/mtp1069-6679190202

Hilbig, B. E., Zettler, I., Leist, F., and Heydasch, T. (2013). It takes two: honestyHumility and Agreeableness differentially predict active versus reactive cooperation. Pers. Individ. Dif. 54, 598-603. doi: 10.1016/j.paid.2012.11.008

Hollebeek, L. D., Juric, B., and Tang, W. (2017). Virtual brand community engagement practices: a refined typology and model. J. Serv. Mark. 31, 204-217. doi: 10.1108/jsm-01-2016-0006 
Jamak, A. B. S. A., Abbasi, A. Z., and Fayyaz, M. S. (2018). Gender differences and consumer videogame engagement. SHS Web Conf. 56:01002. doi: 10.1051/ shsconf/20185601002

Jenny, S. E., Manning, R. D., Keiper, M. C., and Olrich, T. W. (2017). Virtual (ly) athletes: where eSports fit within the definition of "sport". Quest 69, 1-18. doi: $10.1080 / 00336297.2016 .1144517$

Johnson, D., and Gardner, J. (2010). "Personality, motivation and video games," in Proceedings of the 22nd Conference of the Computer-Human Interaction Special Interest Group of Australia on Computer-Human Interaction, (New York, NY: Association for Computing Machinery), 276-279.

Johnson, D., Wyeth, P., Sweetser, P., and Gardner, J. (2012). "Personality, genre and videogame play experience," in Proceedings of the 4th International Conference on Fun and Games, (New York, NY: Association for Computing Machinery), $117-120$.

Kline, R. B. (2015). Principles and Practice of Structural Equation Modeling. New York, NY: Guilford publications.

Kock, N. (2012). WarpPLS 5.0 User Manual. Laredo, TX: ScriptWarp Systems.

Kock, N. (2017). WarpPLS User Manual: Version 6.0. Laredo, TX: ScriptWarp Systems.

Lachlan, K. A., and Maloney, E. K. (2008). Game player characteristics and interactive content: exploring the role of personality and telepresence in video game violence. Commun. Q. 56, 284-302. doi: 10.1080/01463370802240866

Lee, K., and Ashton, M. C. (2004). Psychometric properties of the HEXACO personality inventory. Multivariate Behav. Res. 39, 329-358. doi: 10.1207/ s15327906mbr3902_8

Lee, K., and Ashton, M. C. (2016). Psychometric properties of the HEXACO-100. Assessment 25, 543-556. doi: 10.1177/1073191116659134

Lin, N.-P., Chiu, H.-C., and Hsieh, Y. C. (2001). Investigating the relationship between service providers' personality and customers' perceptions of service quality across gender. Total Qual. Manag. 12, 57-67. doi: 10.1080/ 09544120020010093

Lohse, K., Shirzad, N., Verster, A., Hodges, N., and Van der Loos, H. M. (2013). Video games and rehabilitation: using design principles to enhance engagement in physical therapy. J. Neurol. Phys. Ther. 37, 166-175. doi: 10.1097/npt. 0000000000000017

Loton, D., Borkoles, E., Lubman, D., and Polman, R. (2016). Video game addiction, engagement and symptoms of stress, depression and anxiety: the mediating role of coping. Int. J. Ment. Health Addict. 14, 565-578. doi: 10.1007/s11469-0159578-6

Major, D. A., Turner, J. E., and Fletcher, T. D. (2006). Linking proactive personality and the Big Five to motivation to learn and development activity. J. Appl. Psychol. 91, 927-935. doi: 10.1037/0021-9010.91.4.927

Marbach, J., Lages, C. R., and Nunan, D. (2016). Who are you and what do you value? Investigating the role of personality traits and customer-perceived value in online customer engagement. J. Mark. Manag. 32, 502-525. doi: 10.1080/ 0267257x.2015.1128472

McGrath, D. S., Neilson, T., Lee, K., Rash, C. L., and Rad, M. (2018). Associations between the HEXACO model of personality and gambling involvement, motivations to gamble, and gambling severity in young adult gamblers. J. Behav. Addict. 7, 392-400. doi: 10.1556/2006.7.2018.29

Mills, G. E., and Gay, L. R. (2019). Educational Research: Competencies for Analysis and Applications. Upper Saddle River, NJ: Pearson.

Pannekeet, J. (2018). Newzoo: 2018 eSports Revenue Streams | Global.

Peever, N., Johnson, D., and Gardner, J. (2012). "Personality \& video game genre preferences," in Proceedings of the 8th Australasian Conference on Interactive Entertainment: Playing the System, Auckland, 1-3.

Procci, K., Bowers, C. A., Jentsch, F., Sims, V. K., and McDaniel, R. (2018). The revised game engagement model: capturing the subjective gameplay experience. Entertain. Comput. 27, 157-169. doi: 10.1016/j.entcom.2018.06.001

Przybylski, A. K., and Weinstein, N. (2019). Violent video game engagement is not associated with adolescents' aggressive behaviour: evidence from a registered report. R. Soc. Open Sci. 6:171474. doi: 10.1098/rsos.171474

Reguera, D., Colomer-de-Simón, P., Encinas, I., Sort, M., Wedekind, J., and Boguñá, M. (2020). Quantifying human engagement into playful activities. Sci. Rep. 10:4145.
Reyes, M. E. S., Davis, R. D., Lim, R. A. N. N., Lim, K. R. S., Paulino, R. F., Carandang, A. M. D., et al. (2019). Five-factor model traits as predictors of pathological gaming among selected Filipino gamers. Psychol. Stud. 64, 213-220. doi: 10.1007/s12646-019-00498-y

Sarstedt, M., Hair, J. F. Jr., Cheah, J.-H., Becker, J.-M., and Ringle, C. M. (2019). How to specify, estimate, and validate higher-order constructs in PLS-SEM. Australas. Mark. J. 27, 197-211. doi: 10.1016/j.ausmj.2019.05.003

Sarstedt, M., Ringle, C. M., and Hair, J. F. (2017). Partial least squares structural equation modeling. Handb. Mark. Res. 26, 1-40. doi: 10.1007/978-3-31905542-8_15-1

Sarstedt, M., Ringle, C. M., Henseler, J., and Hair, J. F. (2014). On the emancipation of PLS-SEM: a commentary on Rigdon (2012). Long Range Plann. 47, 154-160. doi: 10.1016/j.lrp.2014.02.007

Seo, Y., and Jung, S.-U. (2016). Beyond solitary play in computer games: the social practices of eSports. J. Consum. Cult. 16, 635-655. doi: 10.1177/ 1469540514553711

Shin, D. (2019). How does immersion work in augmented reality games? A usercentric view of immersion and engagement. Inf. Commun. Soc. 22, 1212-1229. doi: 10.1080/1369118x.2017.1411519

Skoric, M. M., Teo, L. L. C., and Neo, R. L. (2009). Children and video games: addiction, engagement, and scholastic achievement. Cyberpsychol. Behav. 12, 567-572. doi: 10.1089/cpb.2009.0079

Sulaiman, A., Jaafar, N. I., and Tamjidyamcholo, A. (2018). Influence of personality traits on Facebook engagement and their effects on socialization behavior and satisfaction with university life. Inf. Commun. Soc. 21, 1506-1521. doi: 10.1080/ 1369118x.2017.1340495

Teng, C.-I. (2008). Personality differences between online game players and nonplayers in a student sample. Cyberpsychol. Behav. 11, 232-234. doi: $10.1089 / \mathrm{cpb} .2007 .0064$

Topete, H. E. (2010). Personality differences between online game players and non-players. Cyberpsychol. Behav. 11, 232-234. doi: 10.1089/cpb.2007.0064

Ul Islam, J., Rahman, Z., and Hollebeek, L. D. (2017). Personality factors as predictors of online consumer engagement: an empirical investigation. Mark. Intell. Plann. 35, 510-528. doi: 10.1108/mip-10-2016-0193

Van Teijlingen, E. R., Rennie, A. M., Hundley, V., and Graham, W. (2001). The importance of conducting and reporting pilot studies: the example of the Scottish Births survey. J. Adv. Nurs. 34, 289-295. doi: 10.1046/j.1365-2648. 2001.01757.x

Wiebe, E. N., Lamb, A., Hardy, M., and Sharek, D. (2014). Measuring engagement in video game-based environments: investigation of the user engagement scale. Comput. Hum. Behav. 32, 123-132. doi: 10.1016/j.chb.2013.12.001

Worth, N. C., and Book, A. S. (2014). Personality and behavior in a massively multiplayer online role-playing game. Comput. Hum. Behav. 38, 322-330. doi: 10.1016/j.chb.2014.06.009

Xiao, M. (2019). Factors influencing esports viewership: an approach based on the theory of reasoned action. Commun. Sport 8, 92-122. doi: 10.1177/ 2167479518819482

Zeigler-Hill, V., and Monica, S. (2015). The HEXACO model of personality and video game preferences. Entertain. Comput. 11, 21-26. doi: 10.1016/j.entcom. 2015.08.001

Zuiker, S. J., and Anderson, K. T. (2019). Fostering peer dialogic engagement in science classrooms with an educational videogame. Res. Sci. Educ. 1-24. doi: $10.1007 / \mathrm{s} 11165-019-9842-\mathrm{z}$

Conflict of Interest: The authors declare that the research was conducted in the absence of any commercial or financial relationships that could be construed as a potential conflict of interest.

Copyright (C) 2020 Abbasi, Nisar, Rehman and Ting. This is an open-access article distributed under the terms of the Creative Commons Attribution License (CC BY). The use, distribution or reproduction in other forums is permitted, provided the original author(s) and the copyright owner(s) are credited and that the original publication in this journal is cited, in accordance with accepted academic practice. No use, distribution or reproduction is permitted which does not comply with these terms. 